\title{
AULAS DE ASTRONOMIA NO ENSINO FUNDAMENTAL: UMA EXPERIÊNCIA VIVENCIADA NA ESCOLA NETINHA CASTELO NA CIDADE DE SOBRAL - CE.
}

\author{
Sabrina Mara lucas Barbosa ${ }^{1}$, Alexandre Marques Araujo ${ }^{1}$ \\ ${ }^{1}$ Instituto Federal de Educação, Ciência e Tecnologia do Ceará \\ <sabrina_mara16@hotmail.com><xandemarques16@gmail.com>
}

DOI: https://doi.org/10.21439/conexoes.v13i4.1855

\begin{abstract}
Resumo. O presente artigo apresenta uma experiência voltada para o ensino de astronomia nos anos finais do Ensino fundamental, onde foi proposta a sua utilização como elemento motivador que desperta o interesse dos jovens pela ciência e sua curiosidade científica. Discutir sobre astronomia facilita o processo de ensino-aprendizagem da ciência, pois atrai a atenção e desperta o interesse nos alunos. A pesquisa foi desenvolvida em aulas preparatórias para as Olimpíadas de Astronomia e Física do Instituto Federal do Ceará - IFCE e também para a Olimpíada de Astronomia e Astronáutica - OBA, com alunos de $8^{\circ}$ e 9 ano do ensino fundamental, da Escola Netinha Castelo na cidade de Sobral - CE. Foram aulas com abordagens teóricas acerca dos conceito básicos de astronomia, exibição de vídeos, aplicação de simulados e visita ao planetário de Sobral, que compõe o parque da luz, local importante para a astronomia como um todo, por ter sido palco de umas das maiores descobertas científicas da humanidade. Os resultados se mostraram satisfatórios e podem ser avaliados pelas respostas dos alunos no questionário, e pela evolução deles no decorrer das aulas, que demonstraram um aumento na sua curiosidade científica, comprovando assim que se motivaram a pesquisar e se aprofundar no conhecimento da astronomia.
\end{abstract}

Palavras-chaves: Astronomia. Ensino fundamental. Elemento motivador. Curiosidade científica.

\begin{abstract}
This article presents an experience focused on the teaching of astronomy in the final years of elementary school, where it was proposed to use it as a motivating element that awakens young people 's interest in science and their scientific curiosity. Discussing astronomy facilitates the teachinglearning process of science, because it attracts attention and arouses interest in students. The research was developed in preparatory classes for the Astronomy and Physics Olympiad of the Federal Institute of Ceará - IFCE and also for the Astronomy and Astronautics Olympiad - OBA, with 8th and 9th grade students from the Netinha Castelo School in the city of Sobral - CE. There were classes with theoretical approaches about the basic concepts of astronomy, video display, application of simulation and a tour through the Planetarium of Sobral, which makes up the park of light, an important place for astronomy as a whole, because it was the spot of one of humanity's greatest scientific discoveries. The results were satisfactory and they can be evaluated by the students' answers in the questionnaire, and by their evolution during the classes, which showed an increase in their scientific curiosity, thus proving that they were motivated to research and to deepen in the knowledge of astronomy.
\end{abstract}

Keywords: Astronomy. Elementary School. Motivational element. Scientific curiosity

\section{INTRODUÇÃO}

O ser humano nasce com uma curiosidade natural acerca das coisas do mundo que o cerca, na criança essa é uma característica intrínseca, que na maioria das ve- zes se apaga com o passar dos anos, devido a ausência de respostas e de atenção às suas perguntas. Nos últimos anos do ensino fundamental da rede pública e de forma tardia, os estudantes adquirem as primeiras no- 
ções acerca do conhecimento científico, ao estudarem a química e a física, mas é comum nas escolas o fato de que essas aulas são sobrecarregadas de conteúdos, escassas de contextualização, tendendo ao caráter formulístico, e alheio à realidade dos alunos, desconexo da ciência que experienciam no seu cotidiano.

Para se obter êxito no processo de ensino aprendizagem, faz-se necessário antes de tudo, que o educando se sinta motivado a aprender e encontre significado no que lhe é apresentado em forma de conhecimento sistemático, organizado. É dessa forma que o ensino de astronomia surge como fio condutor desse processo, visto que desde os primórdios esse conhecimento acerca da imensidão do espaço que nos cerca intriga e fascina pessoas de todas as épocas, idades e lugares do mundo.

De maneira geral, o ensino de ciências na etapa fundamental ainda não se desvencilhou do tradicionalismo, da forma conteudista e bancária de ensino, onde apenas são lançados conteúdos, e se espera que o aluno decore conceitos e fórmulas para obter êxito em um processo avaliativo centrado na resolução de exercícios, e aplicação de provas. Existe ainda o fato de que os conteúdos de ciências são divididos em etapas, e abordados separadamente, não havendo interdisciplinaridade entre as áreas (física e química), o que dificulta o desenvolvimento do pensamento científico do educando, pois já nos primeiros anos que ele tem contato com essa ciência, recebe uma visão linear e fragmentada, o que o leva a não compreender que a ciência faz parte de um todo e todos seus conhecimentos estão interligados.

\section{A Astronomia no ensino fundamental}

O ensino de astronomia nas aulas de ciências é tema de grande número de pesquisas na área de educação científica. Há um consenso entre os pesquisadores da área que nas salas de aula essa abordagem ainda é bastante escassa, a ciência é fragmentada em áreas que se apresentam desconexas aos estudantes, e isso dificulta o processo de ensino aprendizagem.

A Astronomia, desde tempos remotos, revelou-se uma ciência que desperta curiosidade e fascinação, sendo, no decorrer da história, cunho de entendimento sobre o universo e de estudos direcionados a compreender melhor o porquê de estarmos aqui nesse momento e até onde podemos ir. Ela sempre se mostrou um campo vasto para a evolução da espécie humana. Hoje, não é diferente, principalmente pela evolução das tecnologias (grande parte pela colaboração da própria Astronomia) e dos descobrimentos de novos mundos, abrindo várias possibilidades de irmos mais longe do que já fomos. Por esse motivo a necessidade de implementá-la como parte dos conhecimentos adquiridos no ensino básico dos jovens que terão a oportunidade de experimentar e desvendar os segredos que nos circunda e que tanto se mostra uma área de possibilidades. Silva (2015).

Para compreender o descompasso entre as sugestões para a inserção do ensino de astronomia no ensino fundamental presente nos PCN's, e o que é trazido no livro didático devemos analisar a situação precária de matérias e recursos didáticos para auxiliar o professor, que acaba condicionando suas estratégias de ensino ao conteúdo presente no livro didático, que traz de forma quase invisível tópicos referentes a astronomia, e seu estudo.

Nas escolas de maneira geral não se trabalham conteúdos voltados para astronomia, e nas raras vezes em que isso é visto, os conteúdos são muito superficiais e o ensino dessa ciência está permeado de erros conceituais, que muitas vezes se encontram em materiais impressos destinados aos alunos. É o que afirma ??), que apontam como um dos problemas na deficiência da educação científica que o nível de conhecimento dos professores em temas essenciais de astronomia ainda não alcançou o desejável. Além disso, o docente não preparado para o ensino de Astronomia durante a sua formação promove o seu trabalho educacional com os discentes sobre um suporte instável, se utilizando de fontes não confiáveis desde a mídia sensacionalista até livros didáticos com erros conceituais.

No atual sistema de ensino, onde a carga horária para as ciências é baixa, e muitas vezes os profissionais docentes precisam complementar sua carga horária em mais de uma escola, o livro didático acaba sendo a saída para essa sobrecarga de trabalho, e quando a formação básica em astronomia foi ausente na graduação desse profissional, as aulas abordando esse tema acabam por não ocorrerem, ou quando ocorrem, são realizadas de forma despreparada. Esta questão tem sido debatida por Langhi e Nardi (2005), Langhi e Nardi (2009), que mantém o posicionamento de que os professores estarão contribuindo para possíveis problemas no processo de ensino aprendizagem de astronomia quando baseados apenas em livros didáticos, e continuarem incapazes de realizarem as devidas correções em conceitos erroneamente colocados.

\section{Formação de professores do ensino fundamental}

É comum observar que a grande maioria dos professores que lecionam a disciplina de ciências no ensino fundamental não são graduados na área, e que em alguns casos são formados em química e biologia, o que os leva a trabalharem de forma prioritária conteúdos 
para suas respectivas áreas de especialização, deixando de lado os conteúdo de física, e eliminando qualquer possibilidade de ocorrerem aulas de astronomia nesses anos finais do ensino fundamental. Conforme relata Langhi (2011) "de fato, mediante pesquisas efetuadas na área de Ciências, constata-se uma deficiente formação dos professores neste campo". Além disso, também podemos notar a falta de interesse dos próprios docentes na construção de um currículo mais rico em conteúdo de ciências, pois costumam trabalhar de forma isolada, sem aliar conhecimentos na busca por uma educação formadora de jovens críticos e presentes na construção de uma sociedade moderna e pensante, capazes de intervir positivamente nos acontecimentos que os cercam.

\begin{abstract}
Na Física o tema é mais voltado no eixo terra-universo. Conhecer o sistema solar, os movimentos dos planetas, são assuntos que alunos do último ano do ensino fundamental devem dominar. Na Biologia, os conteúdos são mais voltados para a ecologia e evolução, que deve ser tratada historicamente sobre o surgimento da vida na terra. Na Química, deve-se tratar da origem da luz, reações nucleares e reações químicas. Filho et. Al (2012).
\end{abstract}

É imprescindível apontar uma falha das próprias instituições formadoras de professores para a educação em ciências, visto que nas matrizes curriculares não é ofertada a disciplina de astronomia, e nas poucas vezes que isso ocorre nos cursos de licenciatura em Física, a mesma tem caráter optativo e é destinada para preparação dos interessados em pós-graduações na área, e não contempla absolutamente nada dos conteúdos essenciais para o ensino básico. Nos cursos de biologia e química a disciplina de astronomia sequer aparece e por ironia são exatamente esses profissionais que irão ocupar maior parte das vagas para lecionarem no ensino fundamental. Sabendo dessa problemática, o docente deve buscar o aprimoramento dos conhecimentos, tanto específicos como didáticos, pois é evidente a necessidade de um aprendizado constante tendo em vista que geralmente o período na graduação é curto Lachel e Nardi (2009).

\section{METODOLOGIA}

A pesquisa realizada ocorreu dentro das atividades do Programa Residência Pedagógica do curso de licenciatura em Física do Instituto Federal de Educação, Ciência e Tecnologia do Ceará - campus Sobral, na escola de ensino fundamental Netinha Castelo, também localizada na cidade de Sobral - CE. Foram selecionados pela coordenação da escola, e pelos professores titulares de matemática e ciências um total de 48 alunos que tinham melhores resultados nas avaliações internas, faziam parte das turmas de $8^{\circ}$ e $9^{\circ}$ ano, e estavam inscritos na Olimpíada brasileira de Astronomia e Astronáutica OBA, e na Olimpíada de Astronomia e Física do IFCE que se dá em alusão as comemorações do centenário da comprovação da Teoria da Relatividade, evento ocorrido na cidade de Sobral - CE.

Atuam na escola 8 (oito) residentes do curso de Licenciatura em Física, que foram divididos em quatro duplas, para a execução das atividades, que consistiam de aulas preparatórias para as Olimpíadas citadas, além de possibilitarem o desenvolvimento do pensamento científico e do apresso pela ciência. Cada dupla de residentes se responsabilizou para elaborar um material de estudo semanal, slides, vídeos, experimentos de baixo custo, simulados, e divulgação de sites e livros científicos que seriam utilizados em quatro turmas compostas por doze alunos cada. As aulas ocorriam no contraturno de cada turma, possibilitando a participação de todos. Desde a primeira aula, os alunos se mostraram interessados e apresentaram uma série de dúvidas que foi ponto de partida para a construção de um ambiente favorável ao aprendizado, e gerou nos professores residentes um impacto, pois mostrou que o ensino de astronomia pode despertar interesse e motivar os alunos de uma forma significativa. Vale ressaltar que o projeto teve início com 48 alunos, mas que em seu decorrer esse número aumentou consideravelmente, pois os mesmos divulgaram, e vários outros estudantes procuraram participar das aulas. Na véspera da olimpíada do IFCE, foi aplicado um simulado online com quinze questões que com o intuito de incentivá-los a estudarem e obterem bons resultados, mas acima de tudo de se motivarem ao estudo da Astronomia.

Como forma de apresentar na prática um pouco do que foi abordado nas aulas, foi organizado uma visita ao planetário de Sobral, que compõe o parque da luz, que junto ao Museu do Eclipse que foi erguido em homenagem a umas das maiores descobertas científicas da história descrita por Albert Einstein, a comprovação de que a luz se curva, na expedição liderada por Henrique Morize em 29 de maio de 1919. Essa visita gerou nos alunos entusiasmo e curiosidade sobre a astronomia e a ciência de modo geral, pois tiveram a oportunidade de conhecer in loco a história de uma teoria que modificou a visão newtoniana de universo que perdurou por séculos até a formulação da teoria da relatividade de Einstein em 1905 e sua comprovação em Sobral no ano de 1919. Também foi aplicado um questionário de doze perguntas para perceber as impressões dos participantes acercas aulas de astronomia ministradas na escola. 


\section{RESULTADOS E DISCUSSÃO}

A experiência de ensinar astronomia para alunos dos últimos anos do ensino fundamental se mostrou bastante positiva, com resultados bastante satisfatórios. O retorno dos alunos foi bastante significativo, e as respostas do questionário indicam que esse é um caminho exitoso a se seguir para a melhoria do processo de ensino aprendizagem nas aulas de ciências. As perguntas tinham como finalidade captar as impressões dos mesmos, as perguntas objetivas foram colocadas por já terem sido levantadas durante o decorrer das aulas pelos próprios estudantes, e as perguntas abertas foram respondidas de maneira bastante clara, como se segue:

QUESTÃO 1 - Você já havia tido algum contato com a astronomia antes das aulas preparatórias para as olimpíadas?

Figura 1: Resposta QUESTÃO 1.

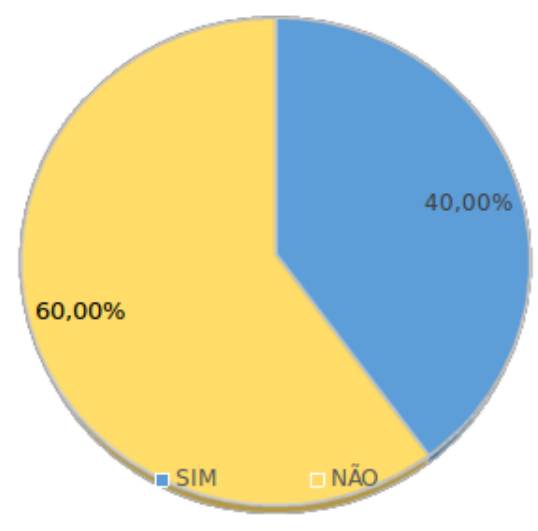

Se sim, esse contato se deu por meio de:

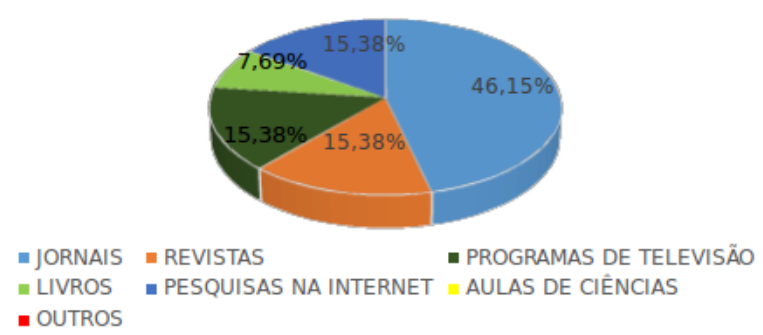

A análise dos gráficos mostra que a maior parte dos alunos não havia tido contato com o ensino de astronomia antes das aulas, mas uma parte considerável possuía noções básicas adquiridas em programas de TV, livros, jornais, aulas de ciências e outros, nos quais eles responderam filmes, jogos e etc. Porém esses conhecimentos prévios dos alunos não eram sistematizados o que não despertava sua curiosidade.
QUESTÃO 2 - Antes da sua participação nas aulas de astronomia ocorridas em sua escola, que visão você tinha dessa área do conhecimento?

Dentre as respostas, listamos algumas que obtivemos:

Aluno 1 - Não sabia de nada, nem a ordem dos planetas.

Aluno 2 - Uma área que estuda os planetas, mas que não era muito importante, era apenas coisa de cientistas, que não tem muita coisa a ver com nossas vidas.

Aluno 3 -Podemos dizer que seria, a lua, sol, planetas etc.

Aluno 4 -Eu não tinha conhecimento sobre esse assunto, até que um dia eu comecei a ir mesmo sem estar participando, mas quando o meu professor disse que podia entrar novos alunos, eu com certeza entrei.

Aluno 5 -Quase nada, apenas coisas bem básicas que são ensinadas no ensino fundamental.

Aluno 6 -Pouco.

Aluno 7 -Não muito.

Aluno 8-Não tinha muito interesse.

Aluno 9 -Uma área da ciência que usava o nosso universo como o princípio de tudo, onde estuda as estrelas.

Por meio dessas respostas eles comprovam que o ensino de astronomia nesta escola é precário e demonstram também um desejo de conhecimento por essa área, visto que o currículo da escola não oferece alternativa ao estudo desse tema. Faz-se necessário uma mediação por parte do professor, e um apoio da instituição de ensino para a construção de uma educação formadora de jovens com pensamento científico.

QUESTÃO 3 - Você considera importante estudar astronomia? Por quê?

Aluno 1 - Sim. Porque a gente tá aprendendo sobre o universo onde vivemos.

Aluno 2 - Sim. Porque ela é incrível, ela nos mostra um mundo que não conhecemos, traz respostas as nossas perguntas mais absurdas, ela é fascinante, e nos diz muito sobre a origem das coisas. 
Aluno 3 - Sim, afinal precisamos por mais pouco ou insignificante sobre onde "vivemos", como fomos parar naquele lugar, e "por que "estamos ate hoje, não só isso. A curiosidade de saber como são realmente os planetas. Os satélites.

Aluno 4 - Sim, pois é algo que aborda muitos assuntos importantes, coisas essenciais para nós, afinal, sem contar que é algo muito interessante.

Aluno 5 - Sim, a vida humana também depende muito da Astronomia.

Aluno 6 - Sim, porque e importante Saber a rotina do dia i várias outras coisas.

Aluno7 - É bom, para aprender.

Aluno 8 - Sim. Porque é importante a gente saber alguma coisa sobre astronomia.

Aluno 9 - Sim, ter um consciente não só da onde a gente mora como tbm o que está em volta de nós é essencial para uma compressão e livre da ignorância.

Diante das conclusões dos alunos eles reconhecem a importância do estudo da astronomia nas suas vidas, e para a sua formação, citando que é relevante conhecer além do que nossos olhos podem ver. Afirmam também que estudo contribui para nossa formação como ser humano nos possibilitando uma visão de mundo mais ampla diante dos acontecimentos científicos que envolve a vida.

A Astronomia sempre despertou curiosidade na humanidade, por esse motivo ela possui qualificação de alto nível em meio ao ensino. Com sua grande variedade de conhecimentos, a Astronomia se mostra uma poderosa ferramenta nas mãos do professor dentro da sala de aula, onde adequadamente causa nos alunos enormes impactos da curiosidade e inquietação, além de entusiasmo e prazer diante de temas sobre a natureza do universo (SOLER; LEITE, 2012).

QUESTÃO 4 - A partir das aulas de astronomia que você participou, você se sentiu motivado à estudar ciências?

Justifique:

Aluno 1 -Estou muito mais interessada, agora que sei um роисо.

Aluno 2 - Pois aprendi coisas novas, que eu nunca imaginei que existia, coisas maravilhosas, sobre o espaço, estrelas, planetas, que traz curiosidade e é fascinante. A Ciência é incrível.

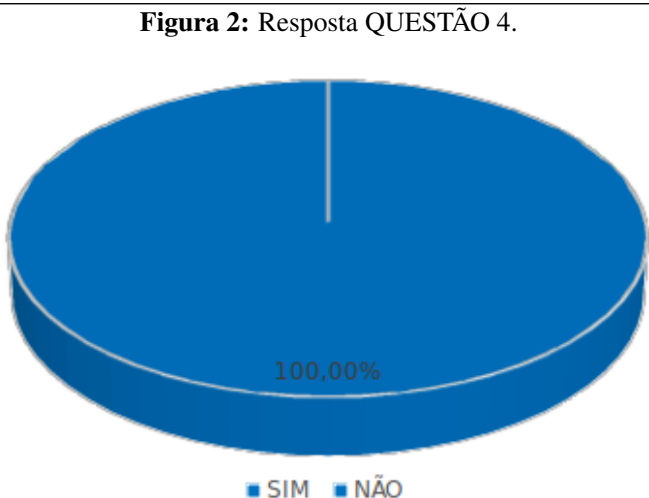

Aluno 3 - Não sei muito bem ao certo, porém chamou a minha atenção e entre outras pessoas. Porque é algo novo, de certa forma já estudado, mas com isso"abrimos os olhos"para a ciência de uma certa forma.

Aluno 4 - Eu sempre gostei de ciências, inclusive desejo futuramente trabalhar nessa área, e eu gosto muito quando tenho a oportunidade de participar de algo em relação a isso, e sempre aproveito as oportunidades, e está estudando astronomia está sendo uma experiência muito boa, estou aprendendo coisas super legais e importantes.

Aluno 5 - Ao ter vivência com o assunto, nem que seja pouco, você passa a ter interesse e vontade de conhecer mais sobre o tema.

Aluno 6 - Achei top.

Aluno 7 - Achei interessante.

Aluno 8 - Pois a gente vontade de aprender mais.

Aluno 9 - Eu senti que essa área combinava comigo.

Os alunos demonstraram estar completamente motivados a conhecer o universo científico, o que confirma a contribuição positiva do projeto realizado escola, deixando um diferencial na instituição mostrando que é possível produzir aulas diversificadas para os estudantes, que os mantenha conectados ao que está sendo transmitido.

QUESTÃO 5 - Você concorda que deveria haver aulas voltadas para o estudo de astronomia já no ensino fundamental?

Justifique:

Aluno 1 - É importante começar de cedo. 
Figura 3: Resposta QUESTÃO 5.

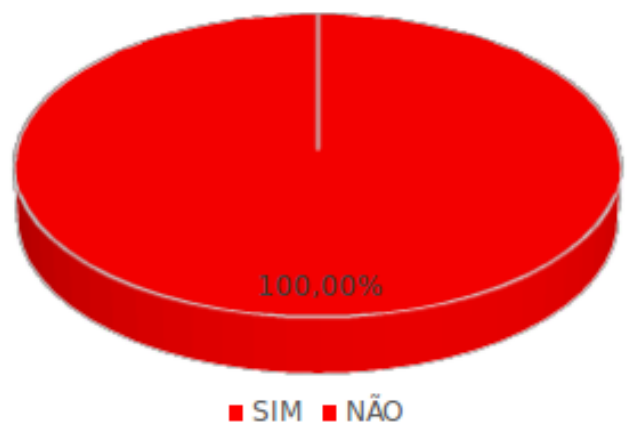

Aluno 2 - Pois seria mais interessante, as aulas traíram conteúdos mais legais que só resolver questões, e ler o livro.

Aluno 3 - Sim, porque esperar por sei lá quantos anos para nos aprofundamos nesses assuntos. Quanto mais cedo melhor.

Aluno 4 - Pois eu acho super importante que aprendamos desde cedo essas coisas, e quanto mais cedo melhor, pois assim incentiva e desperta o interesse sobre esse assunto desde cedo.

Aluno 5 - Quanto mais cedo você ter contato com determinada matéria, menos dificuldade você terá no decorrer do tempo.

Aluno 6 - Seria bom.

Aluno 7 - Ia ser bem legal.

\section{Aluno 8 - Pois todos merecem estudar.}

Aluno 9 - A aulas seriam mais interessantes e tbm é fundamental ter o conhecimento do que são os pequenos pontos que brilham no céu, além de ser uma ciência que usa a matemática, química e fisica como base.

Todos os alunos concordam que deveriam haver aulas de Astronomia no ensino fundamental, e justificam com bastante entusiasmo revelando que no seu ponto de vista isso tornaria as aulas muito interessantes, fortalecendo o processo de ensino aprendizagem da ciência.

QUESTÃO 6 - Você tem interesse em continuar estudando astronomia mesmo após o término das aulas preparatórias para as olimpíadas de astronomia?

Foi bem satisfatória a resposta pois demonstrou que os alunos conseguiram compreender a importância de
Figura 4: Resposta QUESTÃO 6.

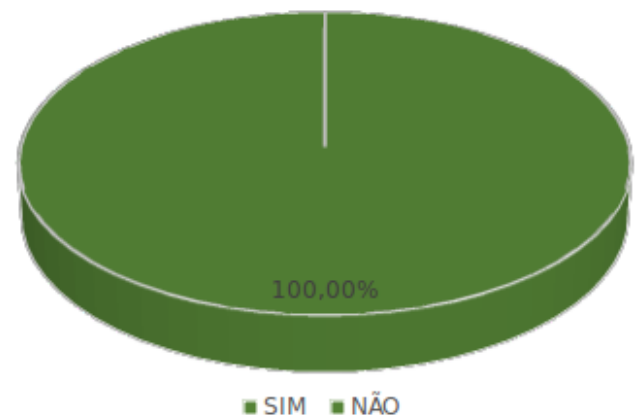

estudar astronomia e captaram essência do conhecimento científico, que é o desejo de conhecer e o espírito questionador intrínseco as ciências da natureza. Para estudar é preciso se sentir motivado, e se os estudantes desejam continuar a aprender sobre as coisas do universo é porque encontraram motivação para tanto.

QUESTÃO 7 - O que você achou da visita ao planetário de sobral realizada durante a preparação para as olimpíadas de astronomia?

Aluno 1 - Muito massa!

Aluno 2 - Foi maravilhoso, é algo inacreditável, maravilhoso de se ver, que tem perto de nós e não conhecíamos antes, quero ir sempre, porque aprendi muito e nunca mais vou esquecer como o universo é incrível.

Aluno 3 - Magnífico. Algo que surpreendeu meus pensamentos, nunca imaginei que a astronomia fosse tão intensa e exuberante quanto o que vi.

Aluno 4 - Eu não pude ir, pois entrei depois, mas eu já fui algumas vezes ao planetário, então já tenho mais ou menos uma noção do que eles fizeram.

Aluno 5 - Ameeei,fiquei impressionada,tudo parecia muito real,muito próximo...Incrível!

Aluno 6 - Achei muito lindo Pow.

Aluno 7 - Foi muito top.

Aluno 8 - Muito legal e interessante.

Aluno 9 - Interessante.

Pode ser visualizado através das respostas nessa questão o encantamento e fascínio que o estudo da astronomia causa nas pessoas. Propiciar um momento como esse é de extrema significatividade, e até mesmo 
um pouco surpreendente porque mesmo residindo em um local tão próximo a esses locais de divulgação do conhecimento científico os mesmos nunca haviam tido oportunidade de conhecer o planetário. O ensino de astronomia envolve entre outras coisas, a contextualização histórica que perpassa por visitas a locais que são marcos para a ciência, observação celeste quando possível, e até mesmo uso de simulações e softwares, quando não se tem locais como o planetário de Sobral.

QUESTÃO 8 - Que sugestões você daria para que o ensino de ciências em sua escola seja mais interessante e motivador?

Aluno 1 - Coisas interessantes sobre o assunto, filmes, documentários, maquetes...

Aluno 2 - Mais aulas de astronomia, vídeos, visitas fora da escola, conversas sobre o universo, e mais coisas legais como as aulas preparatórias pra olimpíadas.

Aluno 3 - Vídeos, explicações que fizessem entender realmente o que é astronomia, que nos aprofundássemos de fato.

Aluno 4 - Que tenha mais olimpíadas e coisas voltadas a ciências, que tenha mais oportunidades aos alunos para fazerem coisas relacionadas ao assunto.

Aluno 5 - Quebrar a rotina de ficar sempre dentro da sala de aula, criar aulas mais dinâmicas, algo assim...

\section{Aluno 6 - Ensinassem Astronomia.}

Aluno 7 - Não sei.

\section{Aluno 8 - Ser mais dinâmico.}

Aluno 9 - Ter aulas práticas, passeios e visitas de profissionais do ramo.

É interessante perceber que os estudantes sentem necessidade de metodologias diversificadas já tão citados nas pesquisas em ensino de astronomia e ensino de ciências como atividades extraclasse em formato de visitas a museus, universidades e instituições de cunho científico e cultural, ou ainda aulas com exibição de filmes e vídeos, atividades experimentais, construção de maquetes e jogos que os possibilitem enxergar da forma mais real possível o que se estuda teoricamente.

Se os estudantes estão sugerindo tais alternativas para um ensino de ciências mais atrativo, presume-se que no mínimo elas são ausentes na sala de aula em que convivem diariamente. Essas sugestões foram desencadeadas através dos minicursos realizados, pois foi mostrado aos alunos que o ensino de ciências pode envolver muito mais que conteúdos expostos no quadro. Para corresponder as expectativas dos alunos toda a comunidade escolar deve se sentir tocada, pois o trabalho do professor também requer apoio pedagógico e financeiro.

Diante execução do projeto os estudantes puderam experimentar aulas com abordagens diferentes da usual, e assim foram capazes de emitir as respostas citadas. Portanto é de extrema relevância ler e entender cada tópico abordado pelos alunos participantes da pesquisa, pois essas sugestões são construtivas e podem orientar a prática docente quanto ao que os alunos anseiam por experimentar e vivenciar no ambiente escolar, e não devem ficar restritas apenas ao professor da disciplina, pois apontam para uma reflexão que deve ser feita por todos os estudantes de graduação e futuros profissionais docentes que se preocupam em contribuir para um ensino de ciências significativo e mais atrativo as novas gerações de estudantes

QUESTÃO 9 - Qual a contribuição que os professores residentes trouxeram para o ensino de ciências na sua escola?

Aluno 1 - Eles são ótimos. Depois de ter aula soube fazer atividades de Ciências sozinha.

Aluno 2 - Nos mostraram q a Ciência é maravilhosa, que a gente não conhecia, e a gente teve uma oportunidade única de aprender e conhecer. As aulas deles foram as melhores de ciências que já vi.

Aluno 3 - Capacidade de ver que além da vida na Terra existem muitos coisas a fora.

Aluno 4 - Estão ajudando bastante, pois além de ensinarem muito bem, eles nos dão a oportunidade de aprender coisas que não iriam aprender com as aulas da escola em si, por isso acho bem importante essas aulas.

Aluno 5 - Não compreendi muito a pergunta, mas acredito que, trouxeram mais vontade de conhecer assuntos da ciências, e fazer com que nós alunos vejamos que a Ciências é muito mais do que imaginamos.

Aluno 6 - Foi uma coisa boa.

Aluno 7 - Mais conhecimento. 
Aluno 8 - interessante, pois nos trouxe novas possiblidades em aprender.

Verificar através das respostas dos alunos que a atuação dos residentes em aulas diversificadas com o ensino de astronomia trouxe contribuições positivas e um impacto benéfico para os estudantes é favorável ao que se pretendeu mostrar, visto que pesquisas diversas apontam para um ensino de ciências voltado para a astronomia como um elemento motivador na educação, capaz de despertar nos estudantes o interesse e a curiosidade científica.

\section{CONSIDERAÇÕES FINAIS}

De maneira geral, percebe-se que o ensino de ciências no nível fundamental de ensino necessita de práticas diversificadas para gerar resultados positivos, e tais práticas existem, estão ao alcance de todos os profissionais docentes que se incumbem em pesquisá-las, e uma das formas que se mostra mais interessante e produtiva é sem dúvidas o ensino de astronomia em uma abordagem conceitual e teórica, que leva os estudantes a exporem suas dúvidas que por vezes estão apenas esperando a oportunidade de emergir, e cria um espaço de diálogo, de conversa, onde suas curiosidades são respondidas, aprimoradas, e transformadas em conhecimento científico.

No que concerne ao trabalho do professor, fica claro que os desafios a serem enfrentados são muitos, bem como baixa carga horária, ou até mesmo sobrecarga de conteúdo, além das deficiências advindas de sua formação que impedem de ministrar conteúdos referentes a astronomia, o que mostra que apenas as pesquisas na área de ensino de astronomia não são suficientes, mas a formação continuada é imprescindível para que esses professores possam se aprimorar e modifiquem suas práticas, tornando o ensino de ciência motivador e interessante.

Verificou-se que a abordagem de temas referentes a Astronomia nas aulas de ciências é de grande importância, tanto para melhorar o ensino e aprendizagem quanto para atrair a atenção dos alunos, tudo isso baseado na experiência vivenciada na escola, e pela concepção dos alunos participantes das aulas.

É imprescindível que a Astronomia esteja realmente presente nas aulas de ciências e seja abordada nos cursos de graduação como algo indispensável a formação do professor. Sendo assim, ela é, desde o passado, de grande importância para o desenvolvimento da ciência e da tecnologia. A Astronomia, Astrofísica e outras ciências espaciais tornaram possíveis grandes jornadas de exploração espacial e possibilitaram o conhecimento e a explicação de vários fenômenos e mistérios do universo (ARAúJO 2010), e por isso não se pode haver ensino de ciências sem abordar um assunto tão significativo e grandioso.

\section{REFERÊNCIAS}

ARAúJO, D. C. C. d. Astronomia no Brasil: Das Grandes Descobertas à Popularização. Dissertação (Trabalho de Conclusão de Curso) - Universidade Católica de Brasília, Brasília, 2010.

BRASIL. Parâmetros Curriculares Nacionais: introdução aos parâmetros curriculares nacionais.

1. ed. Brasília: Secretária de Educação Fundamental, 1997.

LACHEL, G.; NARDI, R. Um Estudo Exploratório sobre o Ensino de Astronomia na Formação Continuada de Professores. 1. ed. São Paulo: Cultura Acadêmica, 2009. 258 p.

LANGHI, R. Educação em astronomia: da revisão bibliográfica sobre concepções alternativas à necessidade de uma ação nacional. Caderno Brasileiro de Ensino de Física, Universidade Federal de Santa Catarina (UFSC), v. 28, n. 2, p. 373-399, 2011.

LANGHI, R.; NARDI, R. Dificuldades de professores dos anos iniciais do ensino fundamental em relação ao ensino da astronomia. Revista Latino-Americana de Educação em Astronomia, v. 1, n. 2, p. 75-91, 2005.

LANGHI, R.; NARDI, R. Ensino de astronomia: Erros conceituais mais comuns presente em livros didáticos de ciência. Caderno Brasileiro de Ensino de Física, Universidade Federal de Santa Catarina (UFSC), v. 24, n. 1, p. 87-111, 2007.

LANGHI, R.; NARDI, R. Ensino da astronomia no brasil: educação formal, informal, não formal e divulgação científica. Revista Brasileira de Ensino de Física, SciELO Brasil, v. 31, n. 4, p. 4402, 2009.

SOLER, D. R.; LEITE, C. Importância e justificativas para o ensino de Astronomia: um olhar para as pesquisas da área. Ii. São Pauloe, 2012. 